\title{
Results after mitral valve replacement with mechanical prostheses in young children
}

\author{
Bahaaldin Alsoufi, MD, ${ }^{\mathrm{a}}$ Cedric Manlhiot, BSc, ${ }^{\mathrm{b}}$ Brian W. McCrindle, MD, MPH, ${ }^{\mathrm{b}}$ Zohair Al-Halees, MD, ${ }^{\mathrm{a}}$ \\ Ahmed Sallehuddin, MD, ${ }^{a}$ Saud Al-Oufi, MD, ${ }^{a}$ Elias Saad, MD, ${ }^{a}$ Bahaa Fadel, MD, ${ }^{a}$ and \\ Charles C. Canver, MD ${ }^{\mathrm{a}}$
}

Objective: We examined outcomes after mitral valve replacement in children younger than 8 years.

Methods: Medical records of patients who underwent mitral valve replacement from 1990 to 2006 were reviewed. Competing-risks methodology determined time-related prevalence and associated factors for death, repeated valve replacement, and survival without reoperation.

Results: In total, 79 patients, median age 24 months (40 days-8 years) underwent 91 mitral valve replacements (10 had repeated procedures). Underlying pathology was congenital heart disease in $95 \%$ of cases. Forty-six patients $(58 \%)$ had undergone previous operations. Operative mortality was $18 \%, 30 \%$ for those 2 -years old and younger and $6 \%$ for those older than 2 years. Competing-risks analysis showed that 10 years after initial mitral valve replacement, $40 \%$ of patients had died without repeated replacement, $20 \%$ had undergone a second replacement, and $40 \%$ remained alive without further replacement. Factors associated with death included higher prosthesis size/patient weight ratio $(P<.0001)$ and longer crossclamp time $(P<.0001)$. Second replacement $6 \pm 4$ years after initial replacement was necessary for 10 survivors. At second replacement, larger prostheses were implanted (mean $24 \mathrm{~mm}$ vs $19 \mathrm{~mm}$ initially). Repeated MVR was associated with younger age at surgery $(p=.006)$. Permanent pacemaker implantation was eventually needed by $11 \%$ of hospital survivors.

Conclusions: Mortality and repeated valve replacement are common after mitral valve replacement in children younger than 8 years, especially younger patients with significantly oversized valves. At valve reoperation, larger prostheses could be implanted, suggesting continued annular growth. (J Thorac Cardiovasc Surg 2010;139:1189-96)

Supplemental material is available online.

Valve repair is the treatment of choice in mitral valve and systemic atrioventricular valve dysfunction ${ }^{1}$; however, mitral valve replacement (MVR) may still be required by a subset of children for whom the mitral valve cannot be repaired. MVR in pediatric patients is associated with distinct clinical and technical problems. ${ }^{2-11} \mathrm{MVR}$ is especially challenging in young children because the small sizes of the native valve annulus, atrium, and ventricle predispose them toward complications related to leaflet entrapment, development of left ventricular outflow tract obstruction, tricuspid valve

\footnotetext{
From King Faisal Heart Institute, ${ }^{\text {a }}$ King Faisal Specialist Hospital and Research Center, Riyadh, Saudi Arabia, and the Labatt Family Heart Center, ${ }^{b}$ the Hospital for Sick Children and the University of Toronto, Toronto, Ontario, Canada.

Received for publication March 25, 2009; revisions received Aug 14, 2009; accepted for publication Oct 25, 2009; available ahead of print March 12, 2010.

Address for reprints: Bahaaldin Alsoufi, MD, King Faisal Heart Institute (MBC 16),

King Faisal Specialist Hospital and Research Center, PO Box 3354, Riyadh, Saudi

Arabia 11211 (E-mail: balsoufi@hotmail.com).

$0022-5223 / \$ 36.00$

Copyright (C) 2010 by The American Association for Thoracic Surgery

doi:10.1016/j.jtcvs.2009.10.038
}

obstruction, and conduction block. In addition to significant morbidity, replacement in this age group has a high operative mortality, ranging from $10 \%$ to $36 \%{ }^{2-14}$ Moreover, MVR in small children is associated with increased late morbidity and long-term anticoagulation, the need for subsequent prosthetic valve replacement as the child outgrows the initial valve, and the deterioration of ventricular function from the development of patient-prosthesis size mismatch. ${ }^{2-14}$

Our aim in this study was to examine factors associated with the mutually exclusive time-related events of death and repeated replacement in young children $(<8$ years) who underwent MVR at our institution.

\section{MATERIALS AND METHODS Inclusion Criteria}

From 1990 to June 2006, a total of 79 consecutive children younger than 8 years required MVR at the King Faisal Heart Institute in Riyadh, Saudi Arabia. Patients were identified from the hospital surgical database. Clinical, operative, and outcome data were abstracted from the medical records. Approval of this study was obtained from the research ethics board at our institution, and requirement for individual consent was waived for this observational study.

\section{Patient Characteristics}

During the study period, 79 patients ( 37 of them male) underwent an initial MVR. Median age at index operation was 24 months (range, 40 days -8 


\section{Abbreviations and Acronyms \\ AVSD $=$ atrioventricular septal defect \\ MVR $=$ mitral valve replacement}

years), and median weight was $9 \mathrm{~kg}$ (range, 3-23 kg). Age distribution at time of initial MVR is shown in Figure E1. The underlying valve disease was congenital mitral valve disease in 73 patients, Marfan syndrome in 2 patients, rheumatic disease in 1 patient, endocarditis in 1 patient, and secondary to other cardiac surgery (Ross procedure and subaortic membrane resection) in 2 patients. Congenital heart disease included isolated mitral valve anomaly in 34 patients, atrioventricular septal defect (AVSD) in 22 patients, atrioventricular discordance (congenitally corrected transposition of the great arteries) with Ebstein malformation in 12 patients, multiple left-sided obstructive lesions (Shone complex) in 4 patients, and other cardiac lesions in 5 patients.

Before MVR, procedures to address mitral valve lesions or other cardiac lesions were performed in 46 patients $(58 \%)$. Other than correction of the AVSD, 20 patients had undergone previous operative attempts at mitral valve repair. The hemodynamic mitral dysfunction was primarily regurgitation in 60 patients $(76 \%)$, stenosis in 11 patients $(14 \%)$, and mixed in 8 patients $(10 \%)$. Of the entire cohort, 69 patients had only $1 \mathrm{MVR}, 8$ patients had 2 MVRs, and 2 patients had 3 MVRs, for a total of 91 operations. Patients' demographic and operative characteristics at initial MVR are listed in Table E1.

\section{Operative Details}

All procedures were performed though midline sternotomy. Cardiopulmonary bypass was established by standard aortic and bicaval venous cannulation. The left ventricle was decompressed by venting through the right superior pulmonary vein. Moderate hypothermia $\left(28^{\circ} \mathrm{C}-30^{\circ} \mathrm{C}\right)$ was used. Myocardial protection was provided with cold blood cardioplegia. In very small infants, deep hypothermic circulatory arrest was occasionally used briefly to improve exposure.

The mitral valve was approached directly by way of the left atrium through the interatrial groove. In certain cases, such as early after AVSD repair or in patients with small left atrium, a transseptal approach was used. Once the decision had been made to replace the mitral valve, the aim was to preserve the posterior mitral leaflet with supporting chordal apparatus. In most patients ( $71 \%$ ), however, this was not possible because of severe deformity of the subvalvular structure or small space that did not allow insertion of an adequately sized prosthesis. The prosthesis was placed within the mitral annulus in all patients. Occasionally, the prosthesis was tilted at the posterior annular level with sutures placed in the left atrium rather than the annulus to permit placement of the large prosthesis $(n=17,22 \%)$. None of the patients had complete supra-annular placement of the mitral prosthesis.

All patients received mechanical valves. Most valves $(n=76)$ were CarboMedics valves (Sorin SpA, Milan, Italy), in addition to St Jude (St Jude Medical, Inc, St Paul, Minn), On-X (On-X Life Technologies, Inc, Austin, Tex), and ATS (ATS Medical, Inc, Minneapolis, Minn) valves ( $\mathrm{n}=1$ each). The median valve size was $21 \mathrm{~mm}$ (range 16-27 mm).

After completion of the MVR, patients underwent intraoperative transesophageal echocardiography to assess prosthetic function. Concomitant cardiac surgical procedures were carried out in 14 cases. Those included tricuspid valve repair $(n=5)$, closure of ventricular septal defect $(n=5)$, debanding $(\mathrm{n}=2)$, relief of left ventricular outflow tract obstruction $(n=2)$, resection of ascending aortic aneurysm $(n=1)$, aortic valve repair $(\mathrm{n}=1)$, right ventricle-pulmonary artery conduit change and pulmonary angioplasty $(n=1)$, and closure of multiple ventricular septal defects $(n=1)$. Mean duration of cardiopulmonary bypass and aortic crossclamp time were $127 \pm 70$ and $79 \pm 33$ minutes, respectively.

\section{Anticoagulation Protocol}

After the operation, once adequate hemostasis had been obtained, all patients were given heparin intravenously to maintain the partial thromboplastin time ratio between 1.5 and 2 times baseline. In addition, all patients received oral warfarin sodium (INN warfarin) aimed at maintaining an international normalized ratio within the range of 2.5 to 3.5. Patients were seen regularly by the pediatric cardiologists, on average 1 visit yearly, and anticoagulation was followed up by specialized local anticoagulation clinics with established anticoagulation protocols. Antiplatelet medications were not routinely prescribed, however, they were given occasionally to a few patients in whom international normalized ratio control was difficult.

\section{Follow-up}

Late outcomes were determined from recent office visits at King Faisal Specialist Hospital and Research Center or from direct correspondence with patients' families. The mean follow-up duration was $4.1 \pm 3.7$ years (up to 14.7 years). Five patients had moved abroad and could not be located, making follow-up $94 \%$ complete.

\section{Statistical Analysis}

Data are presented as mean $\pm \mathrm{SD}$, median with range, and frequency as appropriate. Time-dependent outcomes (death and reoperation) after MVR were parametrically modeled. Parametric probability estimates for time-dependent outcomes used models based on multiple overlapping phases of risk (available for use with the SAS statistical software system [SAS Institute, Inc, Cary, NC] at http://www.clevelandclinic.org/heartcenter/hazard). The HAZARD procedure uses maximum likelihood estimates to resolve risk distribution of time to event in up to 3 phases of risk (early, constant, and late). Competing-risks analysis was performed to model the probability with time of each of 2 mutually exclusive end points, reoperative MVR and death without second MVR, with the remainder of patients being both alive and free from second MVR. Variables potentially influencing the likelihood of outcomes in the competing-risks models were sought from demographic, anatomic, and surgical variables through a bootstrap bagging algorithm (500 samples). Potential risk factors also included multiple mathematic transformations of continuous variables (log, squared, square root, exponential, inverse) and interaction criteria between age at surgery and prosthesis size. Variables appearing in at least $50 \%$ of samples were retained in the final model, which used stepwise regression algorithm $(P<.05$ to enter) to obtain the final model for each phase of risk (Appendix E1). Effects of covariates on the probabilities of outcomes in competing-risks models are given as parameter estimates with percentage reliabilities in the bootstrap algorithm. Clinical relevance of identified covariates to likelihoods of selected outcomes was established by solving the regression equations for multiple "typical" test patients. All statistical analyses were performed with SAS statistical software v9.1.

\section{RESULTS \\ Operative Mortality and Morbidity}

A total of $14(18 \%)$ patients died within the first 30 days after the operation or before hospital discharge. Most deaths occurred in the immediate postoperative period and were cardiac related (low cardiac output syndrome in 9, pulmonary hypertension in 2 , left ventricular outflow tract obstruction in 1, tricuspid valve obstruction in 1, myocardial infarction after left circumflex arterial injury in 1). Complications contributing to death included postoperative hemorrhage in 2 and sepsis and multiorgan failure in 2. Extracorporeal membrane oxygenation support was necessary for 2 patients, 


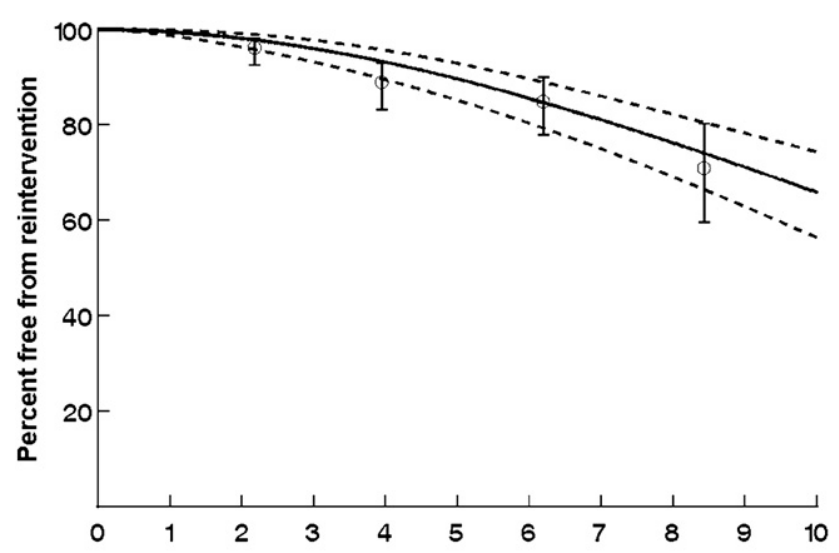

A Years since mitral valve replacement
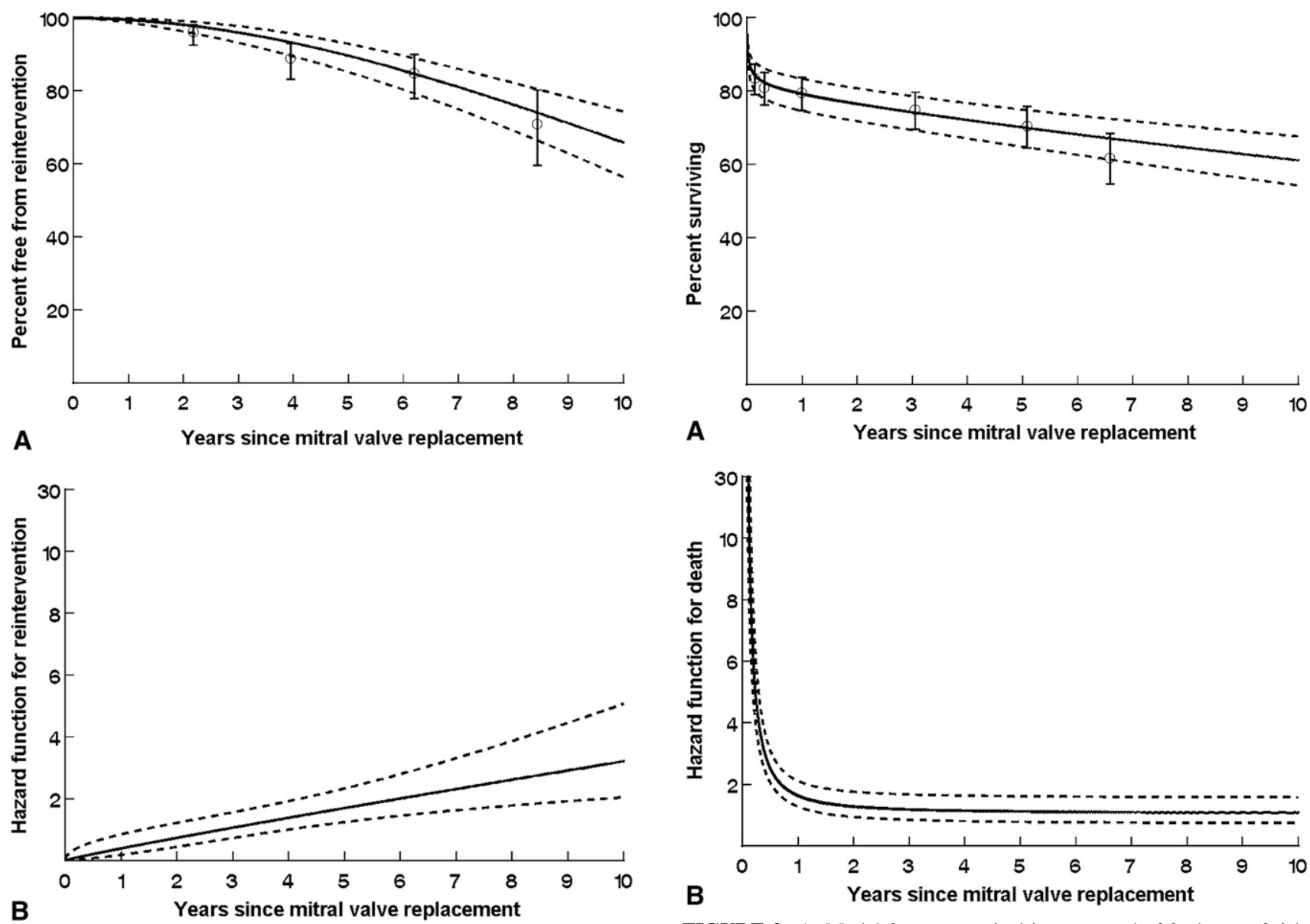

FIGURE 1. A, Model for survival to reoperation has only late phase, because risk of reoperation steadily increases as years since surgery progress. Solid lines represent parametric point estimates, dashed lines enclose $70 \%$ confidence intervals, and circles with error bars represent nonparametric estimates. B, Hazard function for mitral valve reoperation.

neither of whom survived to hospital discharge. Complete heart block necessitating permanent pacemaker implantation was seen in 7 patients (11\% of survivors).

\section{Competing-Risks Analysis for Death or Subsequent Prosthesis Replacement After Initial MVR}

After the 79 initial MVRs, 10 patients had their prosthetic valves subsequently replaced and 24 patients died without further MVR. The hazard function for time-related transition to a second MVR was characterized by the absence of an early phase of risk and by a prolonged late hazard phase, with reoperation rate steadily increasing as years since surgery progressed (Figure 1). The hazard function for time-related transition to death without a second MVR was characterized by an early hazard phase with a high level of risk in the immediate postoperative period and a constant hazard phase indicating a low risk of attrition with time (Figure 2).

FIGURE 2. A, Model for raw survival is composed of 2 phases of risk, early phase with high level of risk in immediate postoperative period and a constant phase indicating low attrition rate with time. Solid lines represent parametric point estimates, dashed lines enclose $70 \%$ confidence intervals, and circles with error bars represent nonparametric estimates. B, Hazard function for death.

The competing-risks analysis for the 2 events showed that at 6 months after surgery nearly $20 \%$ of patients would be expected to have died. Thereafter, the risks of death and reoperation remained constant to 5 years after surgery (affecting a further $10 \%$ of patients each during this period). After 5 years, the risk of death remained low, but the risk of reoperation increased. At 10 years after initial MVR, approximately $40 \%$ of patients had died, $20 \%$ had undergone reoperative MVR, and $40 \%$ remained alive and free from reoperation (Figure 3).

Factors associated with early-phase and constant-phase risks of death and with late-phase risk of subsequent reoperative MVR after initial MVR were sought. Significant factors for early-phase mortality were higher ratio of prosthesis size to patient weight (parameter estimate $0.78 \pm 1.19$, $P<.0001$ ) and longer aortic crossclamp time (parameter estimate $0.58 \pm 1.13, P<.0001$ ). Younger age at MVR was a significant factor for late-phase reoperation risk (parameter estimate $1.19 \pm 0.30, \log$ transformed, $P=.006$; Table 1 ). 


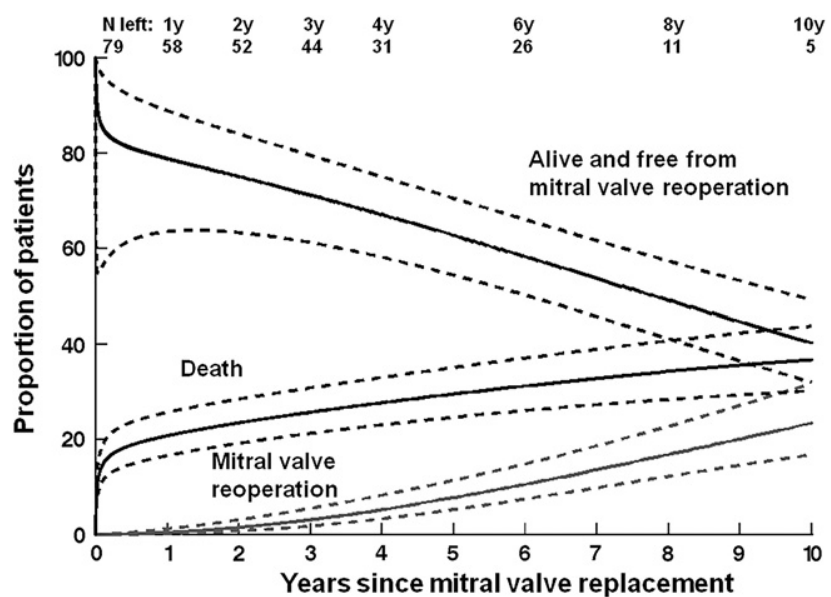

FIGURE 3. Competing-risks analysis depiction of events after initial mitral valve replacement in 79 children younger than 8 years. After initial mitral valve replacement, patients could transition to either death or a subsequent replacement. At any point, sum of percentages of children in each state is $100 \%$. At 10 years after initial surgery, approximately $40 \%$ of patients have died, $20 \%$ have undergone mitral reoperation, and $40 \%$ are alive and free from reoperation.

An interaction between age at diagnosis and prosthesis size was explored as a potential risk factor. Although the interaction was significant as an early-phase risk factor for mortality, the model fit was better (by log likelihood criteria) when expressed as a ratio of prosthesis size to patient weight. The higher risk of death associated with larger ratio of implanted prosthesis size to patient weight ratio is shown in Figure 4. The increased risk of reoperation associated with younger age at initial MVR is depicted in Figure 5.

\section{Outcomes of Second MVR}

Overall, 10 survivors underwent second MVR, on average $6.4 \pm 3.9$ years after the initial MVR. At the time of second MVR, larger prosthesis were implanted (mean, $24 \mathrm{~mm}$ vs $19 \mathrm{~mm}$ initially). Within the study follow-up period, 2 of the patients who had undergone a second MVR required

TABLE 1. Factors associated with time-related death or second mitral valve replacement

\begin{tabular}{lccc}
\hline & $\begin{array}{c}\text { Parameter } \\
\text { estimate } \pm \text { SE }\end{array}$ & $\begin{array}{c}\boldsymbol{P} \\
\text { value }\end{array}$ & $\begin{array}{c}\text { Reliability } \\
(\%)\end{array}$ \\
\hline $\begin{array}{l}\text { Factors affecting risk of death } \\
\text { Early phase }\end{array}$ & & & \\
$\begin{array}{l}\text { Higher prosthetic size/patient } \\
\quad \text { weight }\end{array}$ & $0.771 \pm 1.189$ & $<.0001$ & $52 \%$ \\
$\begin{array}{l}\text { Longer crossclamp time } \\
\quad \text { per 10 min) }\end{array}$ & $0.582 \pm 0.127$ & $<.0001$ & $62 \%$ \\
$\begin{array}{l}\text { Constant phase } \\
\text { No factors identified }\end{array}$ & & & \\
$\begin{array}{l}\text { Factors affecting risk of subsequent valve reoperation } \\
\text { Late phase } \\
\text { Younger age at surgery (log y) }\end{array}$ & $1.192 \pm 0.299$ & .006 & $80 \%$ \\
\hline
\end{tabular}
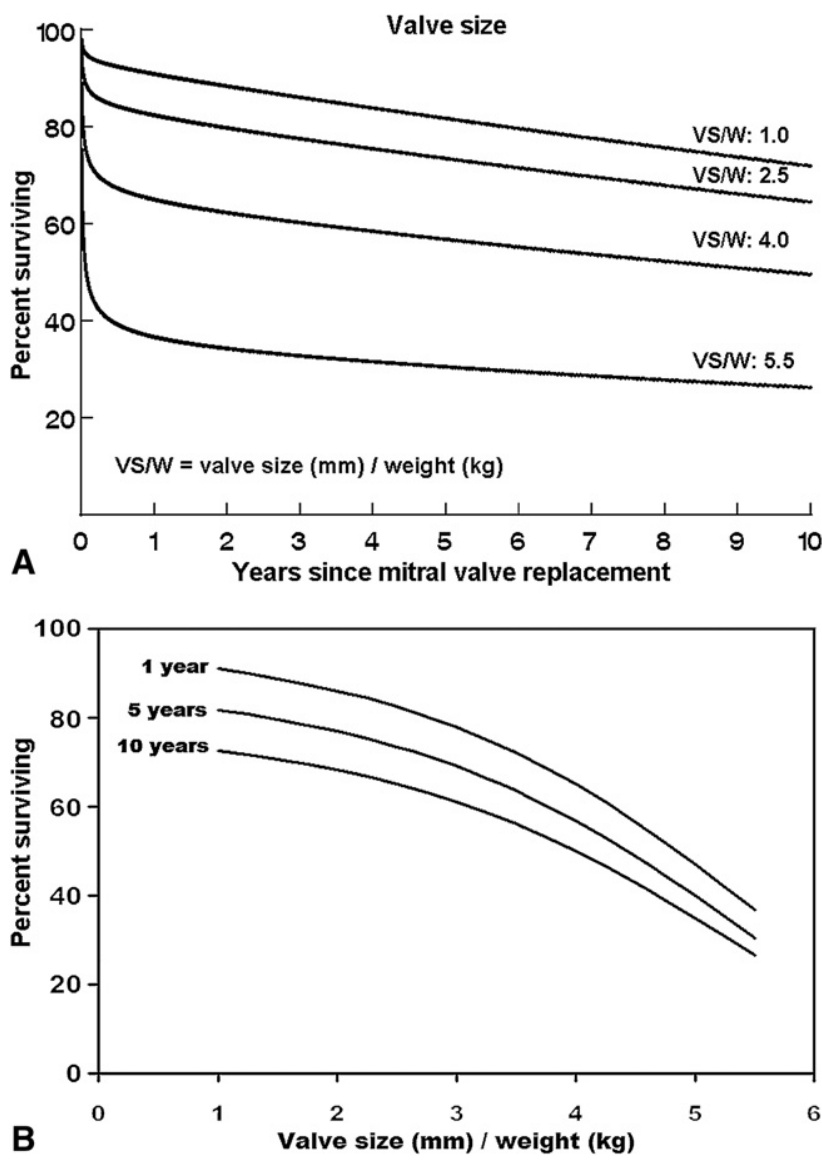

FIGURE 4. Stratified analysis of risk of death by ratio of implanted valve size $(V S)$ to patient weight $(W)$. Unfavorable effect on mortality of higher ratio is shown.

a third MVR, both urgently, for valve thrombosis and a stuck leaflet related to a pannus. After second and third MVRs, there were no deaths, no endocarditis, and no further thrombotic complications beyond those previously described.

\section{Complications}

Overall survivals were $85 \%$ at 1 month, $80 \%$ at 1 year, $73 \%$ at 5 years, and $62 \%$ at 10 years (Figure 6 ). Valve-related complications were infrequent; however, major hemorrhagic episodes occurred in 5 patients (intracranial bleeding in 4 , gastrointestinal bleeding in 1). Three of those hemorrhagic events were trauma related as the result of a fall, and bleeding was the cause of late death in 2 of those cases. In addition, there were 4 documented valve thromboses (excluding sudden cardiac death episodes); 3 patients survived the subsequent required reoperative MVR and 1 died before reoperation. Freedom from valve thrombosis at 10 years was $90 \%$. None of the patients in our series had a documented embolic event or a hospital admission for endocarditis. Overall freedoms from valve-related complications (excluding reoperation or death) were $98 \%$ at 1 year, $83 \%$ at 5 years, and $80 \%$ at 10 years. 


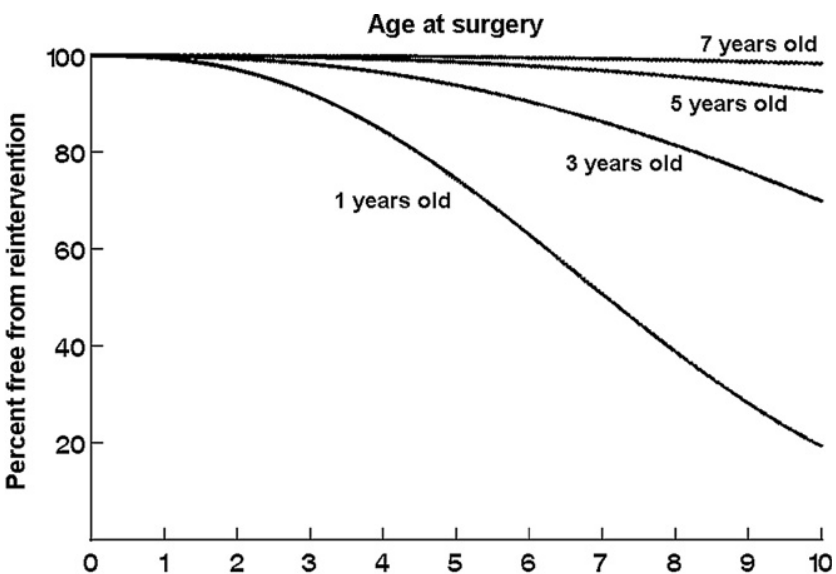

A

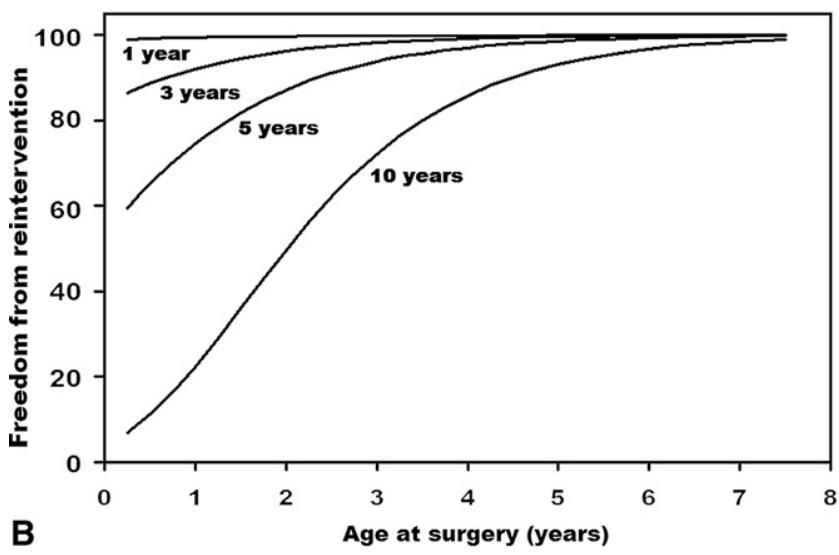

FIGURE 5. Stratified analysis of risk of reoperation by age at initial surgery. Unfavorable effect on mitral reoperation of age is shown.

\section{DISCUSSION}

Our study reports a single institution's experience with MVR in 79 children younger than 8 years. Competing-risks analysis was chosen because these patients were at risk simultaneously for 2 mutually exclusive events, death and reoperation with prosthesis replacement. Conventional time-related analyses consider individual events such as death or reoperation either in isolation or as a combined end point. Although useful, such analyses do not address the question of how often an event may occur in the absence of other events for which a patient is at simultaneous risk.

\section{Mortality}

Early mortality was $18 \%$ in this study, comparable to other reports in which early mortality after initial MVR has ranged between $11 \%$ and $36 \% .^{2-14}$ The reported early mortality after MVR during the first 2 years of life is even higher (as high as $52 \%$ ). Similarly, in our series, operative mortality in children younger than 2 years was $30 \%$, compared with $6 \%$ in children 2 to 8 years old. ${ }^{2-14}$

We identified increased ratio of prosthetic valve size to patient's weight as a significant risk factor for early-phase

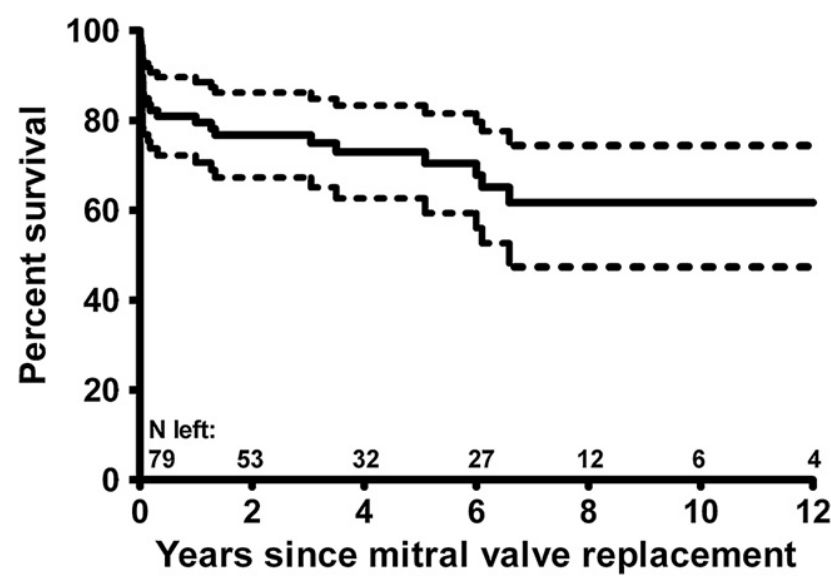

FIGURE 6. Overall freedom from all-cause time-related mortality after mitral valve replacement in children younger than 8 years.

mortality. Most of our patients received prostheses that were relatively larger than the annular size, and in some cases the ratio of prosthesis size to patient's weight was as high as 6.3 (Figure 7). Those patients represent mostly small children with low body weight for whom selection of an oversized prosthesis was inevitable because of the lack of availability of smaller prostheses. Surgeons also may attempt to oversize the prosthesis deliberately in an effort to increase its longevity. Our data suggest that such a strategy of valve oversizing is not advisable. The small sizes of the valve annulus, left atrium, and left ventricle in relation to available prostheses may produce significant geometric disparity, with subsequent potential for leaflet entrapment, left ventricular outflow tract obstruction, tricuspid valve obstruction, circumflex artery injury, and conduction block, all of which may be associated with increased operative risk. ${ }^{2-14}$ All those complications were observed in our series and were associated with significant operative mortality. Recently, after this series and not included in the current patient cohort, 2 infants at our institution showed additional

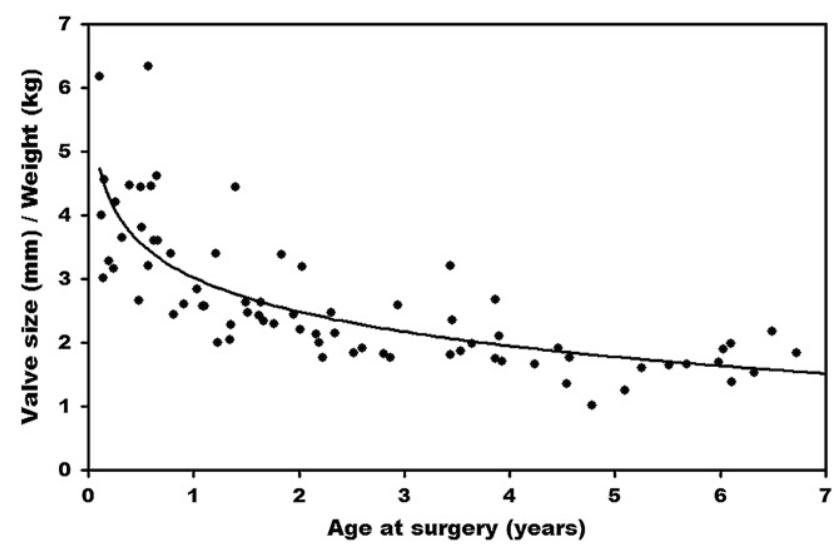

FIGURE 7. Graph showing relationship between ratio of prosthesis size to weight and age. 
complications leading to operative mortality: 1 had additional tricuspid valve obstruction, and 1 had rupture of the posterior wall of the left ventricle in the intensive care unit within 24 hours after MVR. Eleven patients in our series did not survive MVR because of persistent severe low cardiac output state or pulmonary hypertension. Unidentified obstructions of adjacent cardiac structures, including the pulmonary veins, may have also been unrecognized major contributing factors to operative mortality. Although most patients with larger discrepancy between the prosthesis and body weight were very young (Figure 7), this association between early-phase survival and ratio of valve size to patient weight was seen in both younger and older children, as demonstrated in Figure E2.

Other reports have similarly identified larger ratio of prosthesis size to patient weight as a significant risk for mortality. ${ }^{8,10,14}$ Caldarone and associates ${ }^{8}$ noted that geometric disparity according to calculations of ratio of prosthetic valve size to patient body weight affected operative mortality and suggested that other surgical options be considered if the mitral valve couldn't be repaired in those very young patients. Those surgical alternatives might include abandonment of the left ventricle with atrial septectomy and a Damus-Kaye-Stansel anastomosis or heart transplantation. Those options should be carefully considered on the basis of individual patient anatomy, presence of pulmonary hypertension, hospital resources, and individual institutional outcomes.

Ratio of prosthesis size to patient weight mirrored the relationship between the prosthesis and predicted mitral annular diameter. Nonetheless, in a heterogeneous group of children requiring MVR for various cardiac malformations, the actual sizes of the mitral annulus and adjacent cardiac structures vary. ${ }^{11}$ In children with Marfan, idiopathic dilated cardiomyopathy, or other pathologies such as ischemic cardiomyopathy secondary to congenital coronary artery anomalies, the mitral annular diameter may be very large, whereas in those with mitral stenosis from Shone complex, hypoplasia of the mitral annulus and adjacent left heart structures may exist. Some authors have therefore suggested that the use of the $z$ score difference between the prosthesis size and measured annular size is a more suitable parameter to analyze prosthesis-patient mismatch than the ratio of prosthesis size to body weight. ${ }^{11,14}$ Eble and colleagues ${ }^{14}$ measured the difference between the $z$ score of the implanted prosthesis and the $z$ score of the measured mitral annulus. They defined oversizing as a $z$ score difference greater than 1 and undersizing as a difference under -1 . They found that increased $z$ score difference was an independent risk factor for poor outcome. ${ }^{14}$ Ackermann and associates ${ }^{11}$ found that the ratio of prosthesis size to body weight was a significant factor for mortality; when comparing $z$ score differences between the prosthesis and measured annular sizes, however, there was no significant effect of size disparity on survival or reoperation.
Similar to Caldarone, we chose to use ratio of prosthesis size to body weight as a marker of prosthesis oversizing because of its simplicity, the ease with which it can be calculated and the strong association with increased early-phase mortality after MVR. ${ }^{8,10}$ Our results should be interpreted in light of our study limitations. Although the 2 indicators are parallel in most cases, the absolute size of the prosthesis relative to the patient weight may be less important than the size relative to the available annulus. Patients with small annulus and cardiac structures are probably at higher risk for complications related to geometric disparity between the prosthesis and the heart. Our series does not include many patients for whom the measured and predicted annular sizes diverged significantly, and the ratio of prosthesis size to weight therefore seems to be a good representative of prosthesis-patient mismatch.

Additional risk factors that have been identified in previous reports include complete atrioventricular septal defect, Shone complex, diagnosis other than congenital heart disease, and increased cardiopulmonary bypass duration. ${ }^{2-14}$ Longer aortic crossclamp time was also identified as a risk factor for early-phase mortality in our study. This may reflect the complexity of the disease, with adverse effects on cardiac perfusion and other organs due to long cardiac ischemic duration and prolonged exposure to cardiopulmonary bypass.

\section{Reoperative MVR}

We found 1 factor to be associated with higher risk for repeated valve replacement after the initial MVR, and that was younger age at initial surgery. This factor may be a proxy for the fact that patients who require MVR at a younger age usually receive smaller mitral valve prostheses. Although those prostheses are considered too big relative to the left heart structures at time of implantation, as the patient grows, this ratio of prosthesis to patient size reverses and the prosthesis becomes too small and stenotic, causing worsening symptoms and deteriorating cardiac function thus necessitating earlier reoperative MVR.

Moreover, in addition to the effect of the relatively large prosthesis on adjacent cardiac structures, which contributes to early morbidity and mortality as discussed previously, this relatively large prosthesis is subject to leaflet entrapment and generation of inflammatory or immunologic response, which may increase the risk of fibrosis and pannus formation, with possible complications such as valve obstruction or thrombosis requiring early reoperation.

Young age and the need to implant a small prosthesis are unfortunately not modifiable factors, and the only option available to the surgeon is to attempt mitral valve repair in this subgroup of young patients as a temporizing measure until the child has grown older and is able to receive a larger prosthesis. Our data suggest that placement of an 
appropriately sized prosthesis without oversizing is preferable to valve oversizing, although at the probable expense of earlier reoperation requirement. This suggestion is based on three findings. First, significant discrepancy between the prosthesis size and patient weight was found to be a significant risk factor for early mortality. Second, reoperative MVR was not associated with increased operative mortality but rather was associated with lower mortality than that of initial MVR in our experience, as well as in other published reports. ${ }^{8-10,15}$ Finally, after a mean interval of 6.4 years between initial MVR and reoperation (shorter for those who underwent MVR at a younger age), the surgeon was able to place a mitral prosthesis that was on average $5 \mathrm{~mm}$ larger than the explanted prosthesis. This finding suggests that the annulus continues to grow after MVR in young children despite the fixed size of the small prosthesis sewing ring. ${ }^{9}$

\section{Late Complications}

Late valve-related morbidity in our series was limited mainly to bleeding and valve thrombosis. The 10-year freedoms from each of those 2 complications were $90 \%$. Although the risk of anticoagulation-related hemorrhage is not higher than that in adults, the risk of valve thrombosis seems to be higher. ${ }^{16}$ In addition to problems with anticoagulation, local factors such as the relatively large prosthesis size compared with the left heart structures may predispose the patient toward pannus formation and leaflet entrapment and increase the risk of subsequent valve thrombosis. The risk of embolic events relative to that in adults was minimal in our experience and in other series as well. ${ }^{2-14}$

Nonetheless, we should not forget that there has been a steady attrition rate in this young population, with many sudden deaths that are most likely the result of undetected valve-related complications. Moreover, many of our bleeding events were trauma related, with 2 patients dying of trauma-related hemorrhage. This fact highlights the delicate problem of compliance with an anticoagulation regimen, with its implication for patient lifestyle, which is especially difficult to control in young children.

\section{Study Limitations}

This report represents a retrospective analysis of patients from a single institution with diverse anatomy who underwent MVR during a 16-year period. It is subject to all inherent deficiencies associated with any retrospective review. Undoubtedly, indications for valve replacement, timing of operation, and operative technique were not constant with time. In addition, prosthesis selection and operative procedures were neither standardized nor randomized. Finally, although a comprehensive set of variables was used in all analyses, unmeasured covariates may have contributed to disparate outcomes in the recipient populations.

\section{SUMMARY}

The outcome after MVR in children younger than 8 years is associated with a high risk of early death, followed by a late phase of risk associated with low attrition rate despite longterm anticoagulation and the need for subsequent MVR. Discrepancy between prosthesis size and body weight was common in these patients and was associated with higher risk of negative outcomes, with larger discrepancies (greater ratio of prosthetic valve size to body weight) being associated with higher early mortality. Valve oversizing is therefore not recommended, and appropriately sized prostheses should be used to avoid significant geometric disparity with the patient's heart and thus prevent related complications. Normalization of growth in survivors changes the ratio of prosthesis size to body weight with time, and eventually the prosthesis becomes obstructive, thus necessitating earlier reoperative MVR. At of reoperation, larger valve prostheses could be implanted, suggesting continuous annular growth despite fixed prosthesis size. Valve replacement at that time is associated with diminished mortality and increased valve longevity relative to values in younger children.

\section{References}

1. Wood AE, Healy DG, Nolke L, Duff D, Oslizlok P, Walsh K. Mitral valve reconstruction in a pediatric population: late clinical results and predictors of long-term outcome. J Thorac Cardiovasc Surg. 2005;130:66-73.

2. Alexiou C, Galogavrou M, Chen Q, McDonald A, Salmon AP, Keeton BK, et al. Mitral valve replacement with mechanical prostheses in children: improved operative risk and survival. Eur J Cardiothorac Surg. 2001;20:105-13.

3. Günther T, Mazzitelli D, Schreiber C, Wottke M, Paek SU, Meisner H, et al. Mitral-valve replacement in children under 6 years of age. Eur J Cardiothorac Surg. 2000;17:426-30.

4. Erez F, Kanter KR, Isom E, Williams WH, Tam VK. Mitral valve replacement in children. J Heart Valve Dis. 2003;12:25-9.

5. Zweng TN, Bluett MK, Mosca R, Callow LB, Bove EL. Mitral valve replacement in the first 5 years of life. Ann Thorac Surg. 1989;47:720-4.

6. van Doorn C, Yates R, Tsang V, deLeval M, Elliott M. Mitral valve replacement in children: mortality, morbidity and haemodynamic status up to medium term follow up. Heart. 2000;84:636-42.

7. Vohra HA, Laker S, Stumper O, De Giovanni JV, Wright JG, Barron DJ, et al. Predicting the performance of mitral prostheses implanted in children under 5 years of age. Eur J Thorac Cardiovasc Surg. 2006;29:688-92.

8. Caldarone CA, Raghuveer G, Hills CB, Atkins DL, Burns TL, Behrendt DM, et al. Long-term survival after mitral valve replacement in children aged $<5$ years: a multi-institutional study. Circulation. 2001;104(12 Suppl. 1):I143-7.

9. Raghuveer G, Caldarone CA, Hills CB, Atkins DL, Belmont JM, Moller JH. Predictors of prosthesis survival, growth, and functional status following mechanical mitral valve replacement in children aged $<5$ years, a multi-institutional study. Circulation. 2003;(Suppl. 1):108. II174-9.

10. Kojori F, Chen R, Caldarone CA, Merklinger SL, Azakie A, Williams WG, et al. Outcomes of mitral valve replacement in children: a competing-risks analysis. J Thorac Cardiovasc Surg. 2004; 128:703-9.

11. Ackermann K, Balling G, Eicken A, Günther T, Schreiber C, Hess J. Replacemen of the systemic atrioventricular valve with a mechanical prosthesis in children aged less than 6 years: late clinical results of survival and subsequent replacement. J Thorac Cardiovasc Surg. 2007;134:750-6.

12. Kadoba K, Jonas RA, Mayer JE, Castaneda AR. Mitral valve replacement in the first year of life. J Thorac Cardiovasc Surg. 1990;100:762-8. 
13. Daou L, Sidi D, Mauriat P, Butera G, Kachaner J, Vouhé PR, et al. Mitral valve replacement with mechanical valves in children under two years of age. J Thorac Cardiovasc Surg. 2001;121:994-6.

14. Eble BK, Fiser WP, Simpson P, Dugan J, Drummond-Webb JJ, Yetman AT. Mitral valve replacement in children: predictors of long-term outcome. Ann Thorac Surg. 2003;76:853-9.
15. Kanter KR, Forbess JM, Kirshbom PM. Redo mitral valve replacement in children. Ann Thorac Surg. 2005;80:642-6.

16. Emery RW, Krogh CC, Arom KV, Emery AM, Benyo-Albrecht K, Joyce LD, et al. The St. Jude Medical cardiac valve prosthesis: a 25-year experience with single valve replacement. Ann Thorac Surg. 2005;79:776-82. 


\section{Appendix E1. Variables Used in Multivariable Analyses}

\section{Demographic}

Age, weight, body surface area

\section{Mitral valve pathology}

Hemodynamic manifestation (stenosis, regurgitation, mixed), underlying pathology (congenital, endocarditis, rheumatic, connective tissue disease), specific congenital disorders (atrioventricular septal defect, Shone, atrioventricular discordance), previous cardiac surgery

\section{Details of mitral valve surgery}

Prosthesis type, prosthesis size (external diameter size), ratio of prosthesis size to patient weight, ratio of prosthesis size to body surface area, additional cardiac surgery, cardiopulmonary bypass duration, aortic crossclamp duration

\section{Experience}

Date of operation

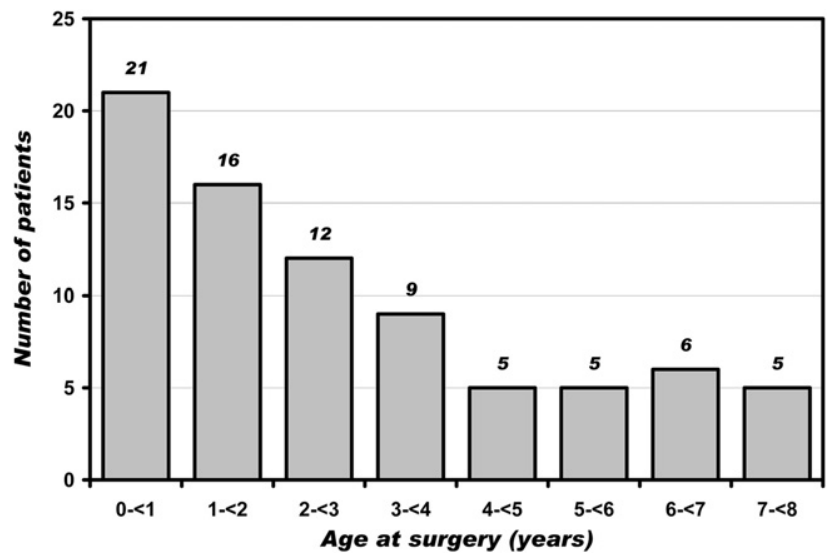

FIGURE E1. Age distribution of patients at initial mitral valve replacement. 

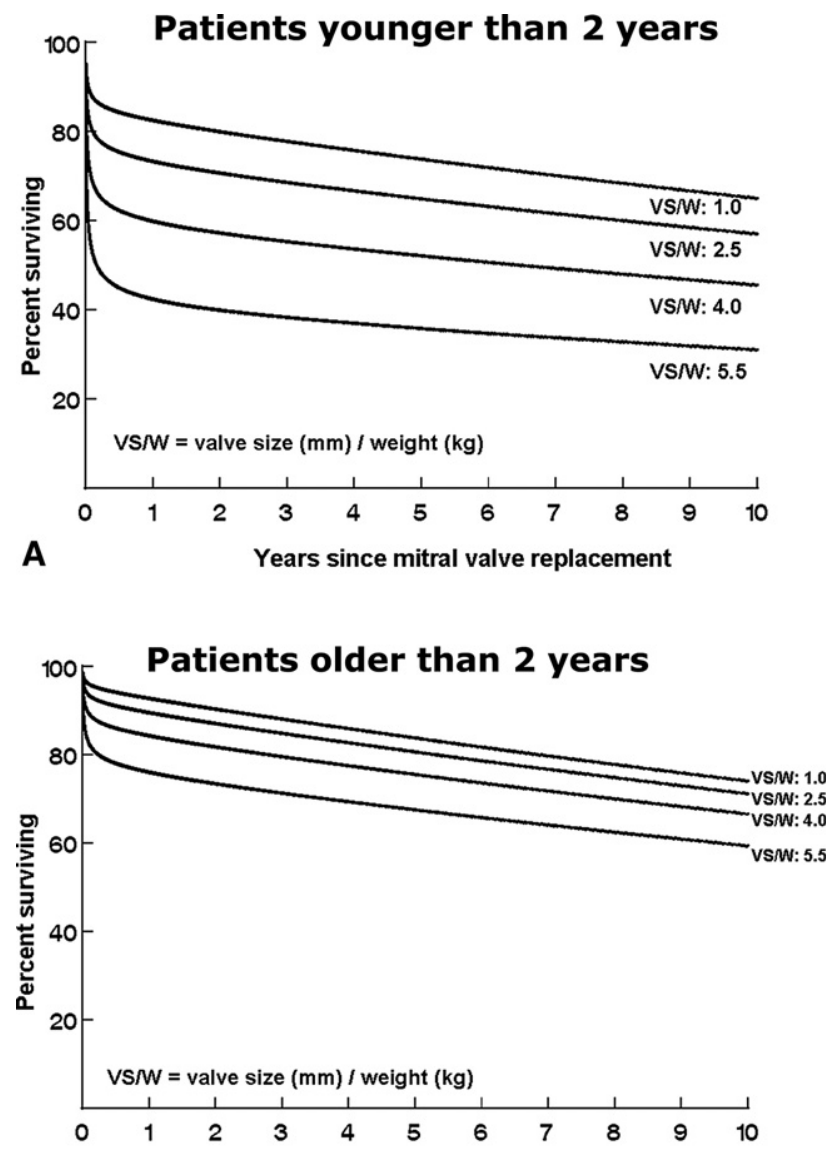

B

Years since mitral valve replacement

FIGURE E2. A, Stratified analysis of risk of death by ratio of implanted valve size $(V S)$ to weight $(W)$ in children younger than 2 years. Unfavorable effect on mortality of ratio is shown. B, Stratified analysis of risk of death by ratio of valve size to weight in children between 2 and 8 years old. Unfavorable effect on mortality of ratio is shown. Graphs clearly show that although risk of death is higher in younger patients than in older ones, ratio of valve size to weight is risk factor for mortality in both groups.
TABLE E1. Demographic and operative variables at initial mitral valve replacement

\begin{tabular}{|c|c|}
\hline \multicolumn{2}{|c|}{ Demographic characteristics } \\
\hline No. of patients & 79 \\
\hline Study dates & 1990-2006 \\
\hline Sex (No. male) & $37(47 \%)$ \\
\hline \multicolumn{2}{|l|}{ Age at surgery $(\mathrm{y})$} \\
\hline Mean $\pm \mathrm{SD}$ & $2.8 \pm 2.3$ \\
\hline Median (range) & $2.2(0.1-8.0)$ \\
\hline \multicolumn{2}{|l|}{ Weight at surgery $(\mathrm{kg})$} \\
\hline Mean \pm SD & $9.8 \pm 4.5$ \\
\hline Median (range) & $9.4(3.0-22.8)$ \\
\hline \multicolumn{2}{|l|}{ Body surface area at surgery $\left(\mathrm{m}^{2}\right)$} \\
\hline Mean \pm SD & $0.47 \pm 0.16$ \\
\hline Median (range) & $0.46(0.23-0.82)$ \\
\hline \multicolumn{2}{|l|}{ Medical history } \\
\hline \multicolumn{2}{|l|}{ Pathology (No.) } \\
\hline Regurgitation & $60 / 79(76 \%)$ \\
\hline Stenosis & $11 / 79(14 \%)$ \\
\hline Both & $8 / 79(10 \%)$ \\
\hline \multicolumn{2}{|l|}{ Underlying congenital anomaly (No.) } \\
\hline Isolated mitral & $34 / 79(43 \%)$ \\
\hline Atrioventricular septal defect & $22 / 79(28 \%)$ \\
\hline Atrioventricular discordance* & $12 / 79(15 \%)$ \\
\hline Shone complex & $4 / 79(5 \%)$ \\
\hline Other & $7 / 79(9 \%)$ \\
\hline \multicolumn{2}{|l|}{ Previous operations (No.) } \\
\hline 1 & $33 / 79(42 \%)$ \\
\hline 1 & $35 / 79(44 \%)$ \\
\hline 2 & $11 / 79(14 \%)$ \\
\hline \multicolumn{2}{|l|}{ Surgical variables } \\
\hline \multicolumn{2}{|l|}{ Prosthesis size (external diameter, $\mathrm{mm}$ ) } \\
\hline Mean $\pm \mathrm{SD}$ & $21 \pm 3$ \\
\hline Median (range) & $21(16-27)$ \\
\hline \multicolumn{2}{|c|}{ Valve size/patient weight at surgery $(\mathrm{mm} / \mathrm{kg})$} \\
\hline Mean \pm SD & $2.6 \pm 1.1$ \\
\hline Median (range) & $2.3(1.0-6.3)$ \\
\hline \multicolumn{2}{|c|}{ Duration of cardiopulmonary bypass (min) } \\
\hline Mean \pm SD & $127 \pm 70$ \\
\hline Median (range) & $107(55-432)$ \\
\hline \multicolumn{2}{|l|}{ Duration of aortic crossclamp (min) } \\
\hline Mean \pm SD & $79 \pm 33$ \\
\hline Median (range) & $69(33-182)$ \\
\hline \multicolumn{2}{|l|}{ Postsurgical outcome } \\
\hline \multicolumn{2}{|l|}{$10-\mathrm{y}$ freedoms $(\%)$} \\
\hline Repeated mitral valve replacement & $71 \%(50 \%-92 \%)$ \\
\hline All-cause mortality (survival) & $62 \%(46 \%-78 \%)$ \\
\hline Thrombosis & $90 \%(80 \%-100 \%)$ \\
\hline Embolism & $100 \%(100 \%-100 \%)$ \\
\hline Bleeding events & $83 \%(72 \%-95 \%)$ \\
\hline Endocarditis & $100 \%(100 \%-100 \%)$ \\
\hline \multicolumn{2}{|l|}{ Duration of follow-up (y) } \\
\hline Mean \pm SD & $4.1 \pm 3.7$ \\
\hline Median (range) & $3.3(0.0-14.7)$ \\
\hline \multicolumn{2}{|c|}{ Duration of follow-up after reoperation (y) } \\
\hline Mean $\pm \mathrm{SD}$ & $4.2 \pm 4.3$ \\
\hline Median (range) & $1.9(0.7-13.0)$ \\
\hline
\end{tabular}

